\title{
SKILL TRAINING SYSTEM OF MANUAL ARC WELDING
}

\author{
BY MEANS OF FACE-SHIELD-LIKE HMD AND VIRTUAL \\ ELECTRODE
}

\author{
Kazuhiko Kobayashi, Shinobu Ishigame, Hideo Kato
}

Chiba University, Japan

\begin{abstract}
We propose a training system of manual arc welding by means of Mixed Reality technique. The system consists of a face-shield-like Head Mounted Display (HMD) and a virtual electrode unit. The former unit is a video-seethrough HMD having almost the same shape and size as an actual face shield. Mixed image of real environmental scene and virtual objects (arc, spatter, etc.) is displayed onto the LCD in the HMD. Moreover, a training assistant function is implemented. As a result, it is confirmed the system is effective in training novice welders.
\end{abstract}

Key words: manual arc welding, training system, face-shield-like HMD, virtual electrode

\section{Introduction}

In recent years, development of robot and computer controlled automation machine in welding is remarkable; the automation technology is applied to mass production jointed by welding. However, skilled welders manufacture particular designed products that are demanded of specifications of materials and shapes, for example a building of steel-frame construction. It is apprehensive of a lack of the skilled welders, similar to other factory skilled workers, caused by automation of welding and deindustrialization of the nation. And furthermore, current skilled welders are aging, so training of young welders is urgent. It is a large barrier to devote to the hard training that is hazardous by high voltage and hot spatters in order to become a skilled welder from novice. To cope with the problem of

The original version of this chapter was revised: The copyright line was incorrect. This has been corrected. The Erratum to this chapter is available at DOI: 10.1007/978-0-387-35660-0_65 
training is not enough, especially rationalization of skill training is demanded.

In the VR technique, the Mixed Reality (MR) technique is a powerful presence method to give a mixed environment (R. Azuma, 2001). A lot of research works apply the MR technique to wearable navigation system (J. Rekimoto, 1997), amusement (T. Ohshima, 1999), portable manual at headset (T. Caudell, 1992), and so on. In future, the MR is going to be used for practical training system, however, the applications are few now.

We developed training systems by means of the MR technique. Manual operations of a lathe machine (K. Kobayashi, 1999) and manual arc welding (K. Kobayashi, 2001a)(K. Kobayashi, 2001b) are the targets of the training systems.

In the present paper, developed devices and an assistant function of the training system for manual arc welding are shown.

\section{Training system of manual arc welding}

In operation of welding, the operator must put on a face shield to protect his face and eyes against strong arc ray. So, the environments of welding compel welders to hard work. Under the condition, it is difficult for novice welder to obtain their skill of welding, while, the simulator promise them to give a similar operation in safety. To seem real to a trainee, one is the real work place, the other is the real tool.

The simulator gives virtual welding scene on the real work place by means of the MR technique. And the similar tools of welding are provided for the virtual welding by the simulator. One is a face-shield-like video-seethrough HMD (Face-shield-like HMD) device; the other is a virtual electrode interaction device (Virtual electrode holder). These devices are controlled by a personal computer. The computer has a video-capture card and an audio card with loudspeakers. ARToolKit (Augmented Reality Tool Kit) for estimate of position and orientation of a camera by means of rectangle markers is used for making the mixed reality images.

The system is compact, so it is used at the real work place of welding.

\section{$2.1 \quad$ Face-shield-like HMD}

The face-shield-like HMD is designed as a video-see-through configuration and same shape of real face shield of welding. Figure 1 shows the HMD. A board CCD camera (1/3inch) is attached on the face-shield for taking real environment image. Then, the image is captured by a videocapture card (PowerMovie PCI, Canopus, Japan) on the computer (IBM- 
PC/AT, CPU: AMD Athlon950MHz, OS:Windows Me, Video: Matrox G400). The computer generate mixed image of real environment and virtual welding objects. The mixed image is projected onto a LCD (5.4inch, STN) inner the face-shield. A strobe light is also attached for expressing the strong ray of electric discharge.

The face-shield HMD gives a sense of handling of tool to a trainee. Timing of covering the face is one of the training.

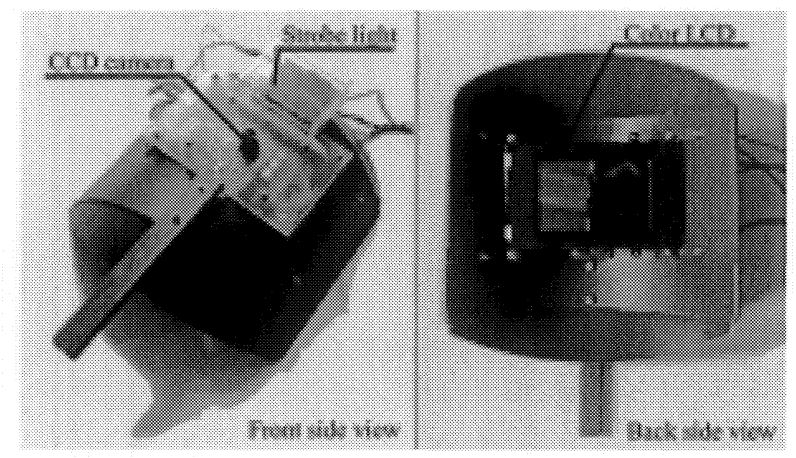

Figure 1. Face-shield-like HMD

\section{$2.2 \quad$ Virtual Electrode}

There is a knack to operate an electrode. A welding rod is shortened due to melting and evaporation in welding. And it often sticks to a work piece due to melting. A welder keeps a gap between the tip of the welding rod and the workpiece to generate arc. Above all, the welder does it under low visual feedback condition to control the electrode. Figure 2 shows the virtual electrode holder unit in order to train the knack. A stepping motor (M42P5A MITSUMI, Japan) pulls up the virtual electrode for simulating the exhaustion of the rod. When the tip of the virtual electrode stays on the plate, the rod stick to the workpiece plate by an electromagnet. There is a reflection-type infrared photo sensor (SG-2BC, KODENSHI, Japan) for measuring the gap between the tip and the plate. A microprocessor (PIC16F873, Microchip, USA) is a slave controller of the personal computer via $\mathrm{RS}-232 \mathrm{C}$ in order to control these parts. 


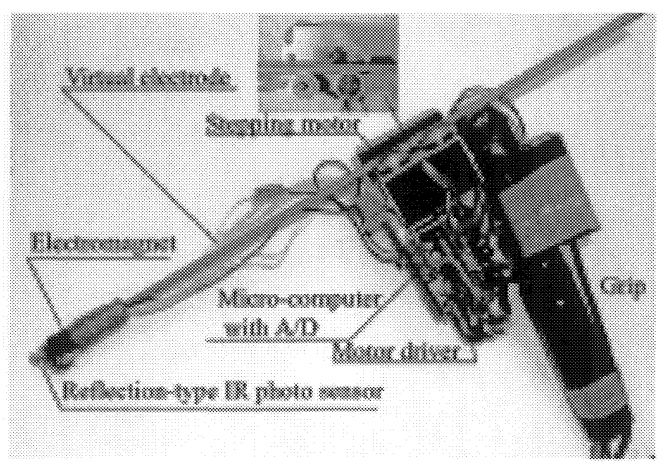

Figure 2. Virtual electrode unit

\subsection{Programs of the simulator}

It is necessary for composing the virtual objects and the real scene to estimate position and orientation of the camera. There are some methods to estimate position and orientation of the camera: to use $3 \mathrm{D}$ position sensor, to use some marker, to use hybrid sensors. Then, the image-based method by means of registration markers is used for the simulator. Movement of operator's head is small in the welding. And, magnetic noise is huge in the factory. Moreover, welding operation needs more accuracy registration; the image-based method is the most accuracy than the methods. The ARToolKit is the powerful library to construct the mixed reality application by means of rectangle markers. So, the simulator uses it for estimate of the camera position and orientation.

It is pasted the rectangle marker $(60 \mathrm{~mm} \times 60 \mathrm{~mm})$ on the workpiece and the virtual electrode holder. The marker of the workpiece represents the world coordinates. Then, position and orientation of the camera of the Faceshield-like HMD is estimated from it. The tip of the virtual electrode is calculated from the marker of the holder and offset by the stepping motor.

In the work area $(300 \mathrm{~mm} \times 300 \mathrm{~mm})$, an error range of the image-based registration is about $3 \mathrm{~mm}$. The simulator uses the output of the photo sensor of the tip of the virtual electrode for measuring the gap to compensate it.

The host computer controls the HMD and the virtual electrode. Figure 3 shows the example of mixed image in the welding simulator. Figure 3(a) is a captured image of CCD camera on the HMD, (b) represents the detection results of markers from (a). Figure 3(c) is mixed image of virtual welding. Workpiece, spatter and electrode holders are computer-generated objects, and the other is real scene. In this scene, two plates are welded with a straight line. Refresh frequency of mixed image is about 12 frames per sec. 
The simulator has an auditory feedback. It is known that skilled welders are able to distinguish sounds of welding. The simulator uses sounds captured by actual welding according to trainee operation.

The parameter used for the model such as the exhaustion speed of the virtual welding electrode contained in the simulator should be set from the actual welding work.

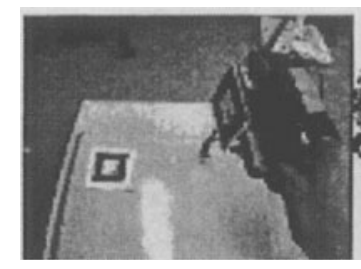

(a) CCD image

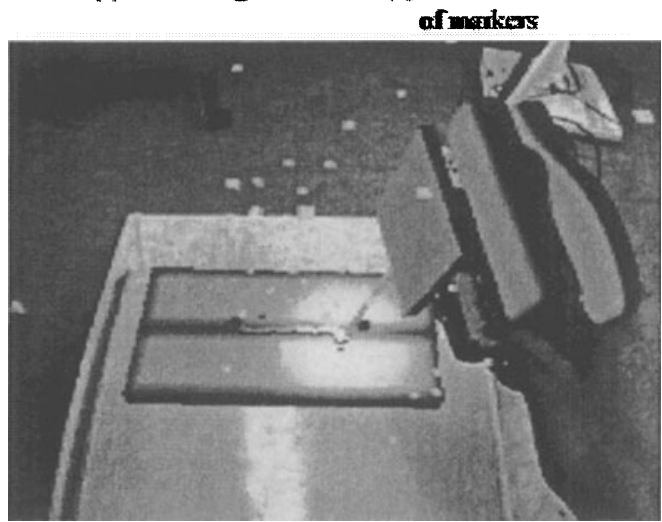

(c) Mixed imase of vintual welding

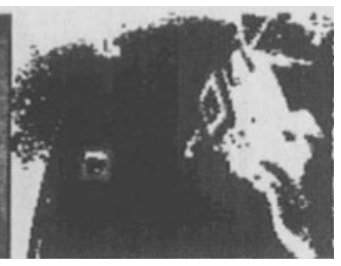

(b) Detection results of monikers

Figure 3. Example of MR image

\subsection{Teaching assistant function}

As for the evaluation of manual arc welding skill, a method by mechanical test of joint strength is general in the qualifying examination. However, a posture during welding work and a feed rate of electrode are necessary for novice welders in order to learn the welding skill. Though developed simulator by itself must be effective in the training of novice operators, for more effective training, a training assist function has been added to the original simulator. It is important to demonstrate points how to improve their welding skill for novice welders. So, we proposed a training assistant function by the welding simulator that function is to show the differences between a skilled welder and a training welder by means of playback their movement and a point of their welding situations. 
Figure 4(a) shows a sample image of play back function. The function represents the trajectory of electrode-tip in 3D, and some graphs that show the estimated value of inclination angle and feed velocity of the virtual electrode. Figure 4(b) shows a sample image of instructions by the function, left picture is ideal goal, and right is operator's score of training subject.

The function shows the instruction texts to give an actual example, "Move quickly!" or "Move slowly!" because the texts is better than numerical value in order to impress their sensuous. Evaluation items of the support function are five: feed rate of welding, inclination angle of electrode, errors of welding path, interruption number of times during welding and efficiency of welding time. Interrupt arc during welding operation causes the defect of metal. So, it is desirable to keep a continuous welding operation.

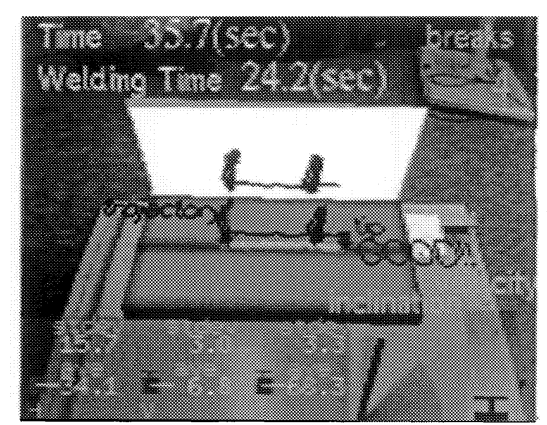

(a) Phybact motion displayed onto the face-slield-Plike HMD

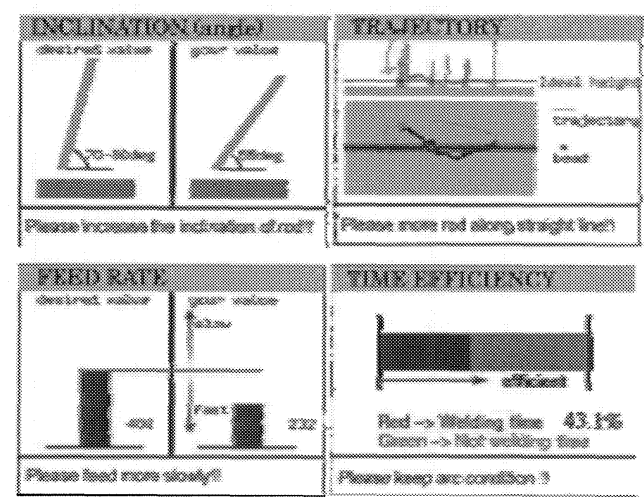

(b) Training assistant information

Figure 4. Training assistant function 


\section{Experiment of Training and Results}

We did a check experiment about training effective by using the simulator. Four students (age 23-25) participated in the experiment. They have no experience about welding. We divided them into two groups: simulator training with teaching assistant function, simulator training without the function. We gave a tiny guidance about welding to them before the test. The operation is straight welding with downward style. They did real welding three times to compare the effectiveness. Then, they trained by the welding simulator 10 times. The last, they did real welding three times, also.

Figure 5(a) shows the score of the welding simulator. Training assistant function affected the score of subjects. Figure 5(b) shows the results of feed rate and angle of electrode in real welding. These results were measured by means of video-recorder.

After the welding training, their performances are near ideal values that were performed by a skilled welder. Especially, the feed rate of training assistant group was amelioration. It is difficult and important to have a sense of speed, because the strength of welding depends on it. Figure 5(c) shows the comparison of weld joint with real welding before and after training. Left lower picture shows that the subject with training assistant had the sense.

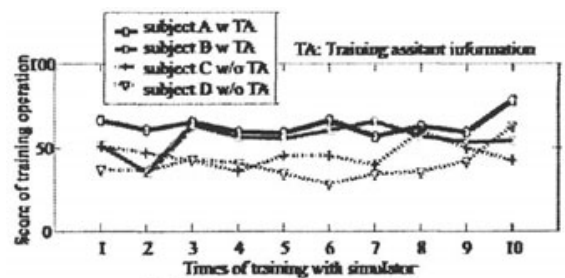

(a) Score of training operation
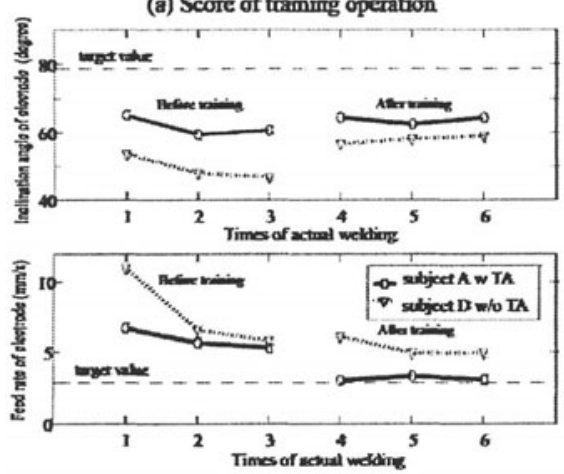

(b) Feod rate and angle of electrode in real welding

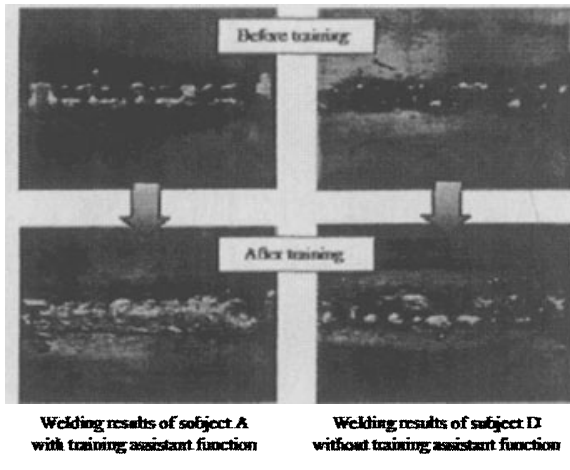

(c) Comparision of weld joint with before and after training 


\section{Conclusions}

Generally welding training needs a foreman. The period of training of welding is several months. The welding simulator with MR technique is able to support the training curriculum. Especially, the training assistant function is effective to practice welding operation with safety.

And, the improvement of the system is necessary when the simulator adopt the training of the more advanced welding skill. For example, skilled welder can observe the welding pool that is a zone of melting metal. To present the situations by the simulator, it needs more precision models of visual and physics of welding.

\section{References}

Augmented Reality Tool Kit. ARToolKit. http://www.hitl.washinton.edu/.

K. Kobayashi, N. Hashimoto, H. Kato (1999). Simulation of boring operation with lathe by means of mixed reality (in Japanese). Trans. Virtual Reality Soc. Japan, 4(4):685-690.

K. Kobayashi, S. Ishigame, H. Kato (2001a). Simulator of manual metal arc welding with haptic display. In Proc. of The 11 th Int'l Conf. on Artificial Reality and Telexistence (ICAT2001), pages 175-178, Tokyo.

K. Kobayashi, H. Kato, S. Ishigame (2001b). A simulator of manual metal arc welding - a visual display system using mixed reality -. In Proc. of The 2nd Int'l Sympo. on Mixed Reality (ISMR2001), pages 143-144, Yokohama.

R. Azuma, et al. (2001). Recent advances in augmented reality. IEEE Computer Graphics and Applications, 21(6):34 - 47.

J. Rekimoto (1997). Navicam: A magnifying glass approach to augmented reality. Presence: Teleoperators and Virtual Environments, 6(4):399-312.

T. Ohshima, et al. (1999). RV-border guards: A multi-player mixed reality entertainment (in Japanese). Trans. Virtual Reality Soc. Japan, 4(4):699-705.

T. P. Caudell, D. W. Mizell(1992). Augmented reality: An application of heads-up display technology to manual manufacturing processes. In Proc. of Hawaii Int'l Conf. System Sciences, pages 659-669. 